\title{
Microfluidic Impedimetric Sensor for Soil Nitrate Detection Using Graphene Oxide and Conductive Nanofibers Enabled Sensing Interface
}

\author{
Md. Azahar Ali ${ }^{1}$, Huawei Jiang ${ }^{1}$, Navreet K. Mahal ${ }^{2}$, Robert J. Weber ${ }^{1}$, Ratnesh Kumar ${ }^{1}$, \\ Michael J. Castellano ${ }^{2}$, and Liang Dong ${ }^{1, *}$ \\ ${ }^{1}$ Department of Electrical and Computer Engineering, lowa State University, Ames, lowa, 50011 USA \\ ${ }^{2}$ Department of Agronomy, lowa State University, Ames, lowa, 50011 USA \\ *Corresponding author. E-mail address: Idong@iastate.edu (L. Dong)
}

\begin{abstract}
This paper reports on a microfluidic Impedimetric nitrate sensor using graphene oxide (GO) nanosheets enabled poly(3,4-ethylenedioxythiophene) nanofibers (PEDOT-NFs) as an electrochemical working electrode. The sensor has demonstrated its capability to detect nitrate ions in real samples extracted from soil. The PEDOT NFs-GO composite serves as an effective matrix for immobilization of nitrate reductase enzyme molecules. The oxygenated functional groups available at $\mathrm{GO}$ allows increasing the charge transfer resistance of the PEDOT NFs-GO based electrode. Systematic microscopic, spectroscopic, and electrochemical studies were conducted to illustrate synergic interactions between the GO and PEDOT NFs. The sensor provides a sensitivity of $61.15 \Omega /(\mathrm{mg} / \mathrm{L}) / \mathrm{cm}^{2}$ within a concentration range of 0.44 $-442 \mathrm{mg} / \mathrm{L}$ for nitrate ions. The detection limit of the sensor is $0.135 \mathrm{mg} / \mathrm{L}$ with good specificity, reliability, and reproducibility.
\end{abstract}

Keywords: Microfluidics; Graphene oxide; Nitrate sensor; Soil sensor 


\section{Introduction}

Nitrate $\left(\mathrm{NO}_{3}{ }^{-}\right)$is a critical nitrogen (N) source for plant growth, ${ }^{1,2}$ but is highly soluble in the soil solution and easily lost to the environment where it can degrade air and water quality. Indeed, the United States Environmental Protection Agency regulates $\mathrm{NO}_{3}{ }^{-}$concentration in drinking water at a maximum of $10 \mathrm{mg} \mathrm{NO}_{3}{ }^{-} \mathrm{N} / \mathrm{L}$ (nitrogen in nitrate per liter) or $44.2 \mathrm{mg} \mathrm{NO}_{3}{ }^{-} / \mathrm{L}$ (nitrate per liter). ${ }^{2}$ Soil nitrate has two major sources: microbial transformation of native soil organic nitrogen and exogenous $\mathrm{N}$ fertilizer inputs. In aerobic soils, heterotrophic microbes convert organic $\mathrm{N}$ to ammonium and chemoautotrophic microbes convert ammonium to nitrate via nitrification. Plants are able to absorb a variety of organic and inorganic $\mathrm{N}$ compounds, but in agricultural soils, nitrate is the major source of $\mathrm{N}$ uptake. ${ }^{1}$ However, due to substantial losses from leaching to water and microbial denitrification, soil $\mathrm{NO}_{3}{ }^{-}$availability often limits crop production. ${ }^{2}$ Currently, measurements of soil $\mathrm{NO}_{3}{ }^{-}$are used by farmers to avoid insufficient $\mathrm{N}$ fertilizer inputs that limit crop production and excessive $\mathrm{N}$ fertilizer inputs that decrease profitability and pollute the environment. However, these tests are relatively inaccurate because the soil must be manually sampled in the field and analyzed in a laboratory, which creates a 510 day delay between measurement and data availability. Rapid and accurate soil $\mathrm{NO}_{3}{ }^{-}$sensing could improve $\mathrm{N}$ fertilizer inputs, thereby increasing profitability and environment quality. Therefore, there is an urgent need to develop sensitive, miniature, and low cost nitrate sensors. ${ }^{3-8}$

Electrochemical sensors often use biochemical receptors to recognize specific target molecules and produce electrical signals by catalytic reaction. ${ }^{9}$ With high sensitivity, sign-to-noise ratio, and selectivity, they have played an important role for real-time measurements of biochemical species in many applications. ${ }^{9-13}$ For nitrate detection, researchers have developed sensors using a variety of chemically modified electrodes based on the principle of electrocatalytic reduction of nitrate ions. ${ }^{4-7,14-19}$ An electrochemical nitrate sensor has been developed using boron-doped diamond electrode modified with copper nanoparticles. ${ }^{18}$ Another electrochemical sensor based on copper nanostructures has also been developed for nitrate determination in foodstuffs and water. ${ }^{19}$ State-of-the-art portable nitrate detection sensors include "NISE sc ISE Nitrate Probe" and "Neulog Nitrate Ion Selective Sensor" by Hach and Neulog, respectively, which are based on potentiometric ion-selective measurements. These existing electrochemical sensors have led to significant improvement toward rapid and low-cost detection of nitrate ions. However, there is still much room for improvement of sensitivity, limit-ofdetection (LOD), portability, consumption of agent and reagent, and cost-effectiveness. In particular, as the critical element, a high-performance bioelectrode of electrochemical sensor requires large 
electrochemical surface area, high loading capacity of receptors, high heterogeneous electron transfer rate, high affinity with target molecules, and easy fabrication.

Recently, poly(3,4-ethylenedioxythiophene) (PEDOT) has attracted much attention, due to its inherent stability, high conductivity, structural uniformity, and biocompatibility. ${ }^{20-23}$ It is one of the most stable conducting polymers available at present. Because the undesired $\alpha, \beta$ - and $\beta, \beta$-couplings are not present within the polymer backbone, PEDOT has high electrical conductivity that ensures fast electron transfer. ${ }^{23,24}$ In addition, the positively charged backbone of PEDOT allows for electrostatic binding with the negatively charged nanostructured materials or bio-species such as cells and enzymes. ${ }^{25}$ PEDOT has been adopted in many applications including biological and chemical sensors. ${ }^{26-28}$ Recently, it has also shown that combining two-dimensional graphene oxide (GO) nanosheets with PEDOT could improve surface functionality of PEDOT, owing to the presence of several oxygen-containing surface functionalities of carbon (e.g., epoxide, hydroxyl, and carboxylic groups) at GO. ${ }^{29-36}$ This has led to improved performances of electrocatalysts ${ }^{35}$ and biosensors. ${ }^{36}$

With recent advances in nanotechnology, functionalized one-dimensional (1D) conducting polymer nanostructures (CPNs), including nanofibers (NFs) ${ }^{37-38}$ have offered favorable properties for chemical and biological sensing due to their large surface area, high conductivity, controllable composition, and fast electron transfer of a recognition event along their longitudinal axis. ${ }^{39,40}$ In the past decade 1D CPNs have been extensively investigated for use in many environmental monitoring and biomedical diagnostics applications. ${ }^{39,41}$ PEDOT NFs have also been developed using electrospinning, an inexpensive nanomanufacturing technique. In order to develop applications with PEDOT NFs for detecting biochemical molecules, ${ }^{39}$ several methods have been used to facilitate surface functionalization of PEDOT NFs, including using polystyrene, ${ }^{42}$ carboxylation by acid treatment ${ }^{44}$, alkynes functionalization by click-reaction ${ }^{44}$, microemulsion polymerization with acid ${ }^{45}$, and perfluorofunctionalization by electro-polymerization. ${ }^{46}$

In this paper, we report on the development of a microfluidic impedimetric sensor for detecting nitrate ions, using electrospun PEDOT NFs conjugated with both GO nanosheets and nitrate reductase (NiR) enzyme molecules as an electrochemical bioelectrode. The PEDOT NFs-GO composite is dropcoated on a gold $(\mathrm{Au})$ electrode to form the working electrode (WE) of the microfluidic electrochemical sensor that integrates a $\mathrm{Au}$ counter electrode $(\mathrm{CE})$ and a silver/silver chloride $(\mathrm{Ag} / \mathrm{AgCl})$ reference electrode (RE) inside a channel (Fig. 1a). The abundant functional groups (e.g., carboxyl and hydroxyl) of 
GO nanosheets facilitate immobilizing enzyme molecules on the surface of electrospun PEDOT NFs via EDC-NHS coupling chemistry for efficient catalytic reaction with nitrate ions, and provide a high charge transfer resistance $\left(R_{\mathrm{ct}}\right)$ for the NiR/PEDOT NFs-GO electrode (Fig. 1b). Quantification of nitrate ion concentration in a real liquid sample extracted from soil is performed on the fabricated sensor by an electrochemical impedance spectroscopy (EIS) method. High sensitivity of the sensor is obtained due to a high electrochemical surface area and an improved heterogeneous electron rate of the PEDOT NFs-GO composite. High selectivity of the sensor is achieved by the use of enzyme molecules covalently anchored on the surface of GO nanosheets. By leveraging the excellent properties of PEDOT NFs-GO composite with the intrinsic benefits of microfluidics such as their portability, requirement of minimal amounts of samples and reagents, fast response time, and parallelization, ${ }^{47}$ the integration of PEDOT NFs-GO composite into a microfluidic sensor enables a promising platform for detection of nitrate ions. To our knowledge, there is no report available on constructing a microfluidic nitrate sensor using the PEDOT NFs-GO composite with high sensitivity and specificity.

\section{Experimental}

\subsection{Device fabrication}

Details of fabricating a polydimethylsiloxane (PDMS) microfluidic channel, and $\mathrm{Au}$, and $\mathrm{Ag} / \mathrm{AgCl}$ electrodes on a glass substrate are described in Supplementary Information. Detail of chemicals and synthesis of PEDOT NFs by electrospinning ${ }^{42}$ are given in the Supplementary Information (Fig. S1).

Well-dispersed solution was prepared by mixing $0.4 \mathrm{mg}$ of GO nanosheets and $1 \mathrm{mg}$ of PEDOT NFs powders in $1 \mathrm{~mL}$ ethanol and sonicated for 2 hours at room temperature $\left(21^{\circ} \mathrm{C}\right)$. Before deposition of the PEDOT NFs-GO composite, the Au electrode was treated with oxygen plasma to obtain a hydrophilic surface. $50 \mu \mathrm{L}$ of this solution spread onto the Au surface by drop casting. The electrode was then dried for two hours in air at $40{ }^{\circ} \mathrm{C}$. The surface of the PEDOT NFs was covered with the GO nanosheets due to $\pi-\pi$ interactions ${ }^{48}$ or electrostatic interactions (Fig. S2, Supplementary Information). For control studies, the PEDOT NFs were also deposited on the surface of Au electrode without incorporating GO nanosheets.

NiR enzyme was immobilized on the surface of PEDOT NFs-GO electrode via EDC-NHS chemistry. The $-\mathrm{COOH}$ groups at the $\mathrm{GO}$ surface allowed for covalent binding with $-\mathrm{NH}_{2}$ groups of enzyme molecules by formation of C-N amide bond. $20 \mathrm{~mL}$ of a mixture of EDC and NHS at the volume ratio of 1:1 was dropped onto the PEDOT NFs-GO surface where the EDC $(0.2 \mathrm{M})$ acted as a coupling agent and 
NHS $(0.05 \mathrm{M})$ as an activator. $10 \mu \mathrm{L}$ of a NiR solution $(3.5 \mathrm{mg} / \mathrm{mL})$ was dropped and spread onto the GO activated surface and then kept for 12 hours under a humid condition at $4^{\circ} \mathrm{C}$. To remove any unbound enzyme molecules on the electrode surface, the PBS solution was used to wash the electrode surface. This process allowed forming $\mathrm{C}-\mathrm{N}$ bond between $-\mathrm{COOH}$ groups at $\mathrm{GO}$ and $-\mathrm{NH}_{2}$ groups at $\mathrm{NiR}$ enzyme as evident by the Fourier transform infrared spectroscopy (FT-IR) and X-ray photoelectron spectroscopy (XPS) analyses. After the modification the WE with the PEDOT NFs-GO composite and NiR enzyme, the PDMS channel was treated by oxygen plasma and then bonded to the glass slide containing all the WE, CE and RE electrodes. Therefore, the microfluidic sensor was realized.

\subsection{Extraction of Analyte Solutions from Real Soil Sample and Calibration of Nitrate Level}

For the determination of nitrate levels, soil samples were collected from a Zea mays farm field with different intensities of artificial drainage (artificial drainage is common in Z. mays production fields). Soil moisture content of each sample was determined by weighing $10 \mathrm{~g}$ of field moist soil in an aluminum (Al) boat. Samples were dried at $105^{\circ} \mathrm{C}$ until constant mass, and the gravemetric moisture content was calculated by mass of water per unit mass of dry soil (g/g) (Table S1, Supplementary Information). To extract nitrate from each sample, 11-14 g of field moist soil was weighed in five specimen cups. $50 \mathrm{~mL}$ of $2 \mathrm{M} \mathrm{KCl}$ solution was added to each specimen cup and shaked on a reciprocal shaker for $1 \mathrm{hr}$. Then, the solutions were filtered using Whatman \#1 filter paper into $50 \mathrm{~mL}$ centrifuge tubes and the filtrates were kept frozen until analyzed.

To prepare real nitrate samples, $1000 \mathrm{mg} / \mathrm{L}$ of $\mathrm{KNO}_{3}$ standard stock solution was prepared and diluted into eight different concentrations ranging from 0 to $44.2 \mathrm{mg} / \mathrm{L} \mathrm{of} \mathrm{NO}_{3}{ }^{-} .50 \mu \mathrm{L}$ of each standard stock solution and soil extracts were pipetted into conventional 96-well microplate using an electronic pipette. Subsequently, $250 \mu \mathrm{L}$ of reagent $\mathrm{VCl}_{3} /$ Griess-llosvay solution was added into each microplate

well, and kept at dark place for $24 \mathrm{hrs} .{ }^{49}$ Using the PowerWaveX Select Scanning Microplate Spectrophotometer, the absorbance signals recorded at a fixed wavelength of $540 \mathrm{~nm}$ of monochromatic light. The absorbance signal increased with the increase in concentration of nitrate ions (Fig. S3a, Supplementary Information). The linear relation of absorbance-concentration plot (standard curve) for known standards was determined: $y=0.331 x+0.156 ; r^{2}=0.9951$ (Fig. S3b). Table S2 (Supplementary Information) shows the concentrations of $\mathrm{NO}_{3}{ }^{-}$obtained from the extracted soil samples. One of these $\mathrm{NO}_{3}{ }^{-}$samples was diluted into different concentrations from 0.044 to $44.2 \mathrm{mg} / \mathrm{L}$, for characterizing the capability of the sensor to detect nitrate ions for real samples. 
In order to perform measurements inside the fabricated microfluidic device, the extracted sample solutions were loaded into a syringe $\left(1 \mathrm{~mL}, \mathrm{BD}\right.$ Luer-Lok $\left.{ }^{\mathrm{TM}}\right)$ and infused into the device using a syringe pump (KDS 210, KD Scientific) through a needle and microfluidic tubing.

\section{Results and discussion}

\subsection{Microscopic studies}

Fig. 2a shows scanning electron microscopy (SEM) image of the as-synthesized PEDOT NFs with an average diameter of $\sim 500 \mathrm{~nm}$. They appear in the mixed form of individuals and bundles of fibers. The soldered junctions of fibers are observed, presumably because of strong electrostatic interaction between individual fibers. ${ }^{42}$ Fig. $2 \mathrm{~b}$ shows the PEDOT NFs deposited on the surface of oxygen plasma treated Au electrode. It is found that the as-synthesized long PEDOT NFs were fragmented into short rods due to the sonication treatment prior to the deposition. The attachment between Au and PEDOT NFs occur owing to the covalent interactions of the sulphur atoms present in the NFs with the Au substrate. Fig. 2c shows the individual fragmented rod at a high magnification. The GO nanosheets coated on the PEDOT NFs are clearly seen in Fig. $2 d$. The close-up of the rod (Fig. 2e and f) indicates the presence of GO wrinkles on the surface of PEDOT. The wrinkle formation on the surface of PEDOT may further facilitate the immobilization of the NiR enzyme molecules via formation of C-N amide bond.

For TEM studies, the fragments of PEDOT NFs with GO nanosheets were dispersed in ethanol ( $\geq$ 99.5\% purity) by sonication and drop-casted onto holey carbon copper grids for imaging. Images in Fig. $3 a$ and $b$ show the overview of the dispersed PEDOT NFs and the soldering of PEDOT NFs. Fig. 3c shows an individual PEDOT NF with a core material, which presumably is PVP. The folding and wrinkles of GO nanosheets are seen on the surface of holy carbon grid (Fig. 3d and e). The (002) and (004) planes of GO appear in the selected area diffraction (SAED) pattern due to the crystalline structure of GO (Fig. 3e). The covering of GO nanosheets on the surface of PEDOT NFs is shown in Fig. 3g-i. Fig. 3h and $\mathrm{i}$ also depict the modification of GO nanosheets on the entire surface of PEDOT NFs due to their electrostatic interactions. The appearance of more rings for the SAED pattern of GO sheets with PEDOT NFs (inset of Fig. 3i) indicates the GO coating on PEDOT NFs.

\subsection{Spectroscopic Studies}

In this section, the spectroscopic studies were systematically carried out to confirm the formation of PEDOT NFs-GO nanocomposite and the immobilization of NiR enzyme on the surface of the 
nanocomposite by quantifying important functional groups such as $\mathrm{C}-\mathrm{O}, \mathrm{C}-\mathrm{C}$, and $\mathrm{C}=\mathrm{C},-\mathrm{COOH}$ present in the nanocomposite.

For quantitative confirmation of surface functionalization, we conducted elemental analyses using energy-dispersive X-ray (EDX) spectra for the PEDOT NFs and PEDOT NFs-GO before and after NiR enzyme immobilization (Fig. S4 in Supplementary Information). The C and O elements increase by $\sim 40 \%$ and $\sim 50 \%$, respectively, after the immobilization, confirming the efficient incorporation of the enzyme molecules. More details of EDX studies are given in the Supplementary Information.

Raman spectroscopy measurements were conducted for the PEDOT NFs-GO composite (Fig. S5a in Supplementary Information). The PEDOT NFs show several Raman peaks at 996, 1139, 1202 and $1363.8 \mathrm{~cm}^{-1}$, due to oxyethylene ring deformation, C-O stretching, C-C inter-ring, and C-C stretching in plane modes, respectively. The dominant peaks at 1447 and $1505 \mathrm{~cm}^{-1}$ are assigned to $\mathrm{C}=\mathrm{C}$ stretching in plane modes (antisym.) and $\mathrm{C}=\mathrm{C}$ stretching in plane modes (sym.), respectively. The peaks at 1590 and $1641 \mathrm{~cm}^{-1}$ correspond to quinoid structure and thiophene ring vibration of NFs, respectively. In the case of GO, the peaks at $1350 \mathrm{~cm}^{-1}$ and $1603 \mathrm{~cm}^{-1}$ correspond to disorder (D) and graphitic (G) modes, respectively. The atomic layer of $\mathrm{GO}$ is calculated to be $0.632 \mathrm{~nm}$, indicating that there are about two layers of GO nanosheets (Eq. S1 in Supplementary Information). The peaks at $1350 \mathrm{~cm}^{-1}, 1447$ and 1505 $\mathrm{cm}^{-1}$ seen in the PEDOT NFs remain unshifted while incorporated with GO nanosheets. The peak at 1587 $\mathrm{cm}^{-1}$ may be due to overlapping of graphitic $\left(1603 \mathrm{~cm}^{-1}\right)$ and quinoid structure $\left(1590 \mathrm{~cm}^{-1}\right)$ peaks, indicating the successful incorporation of GO nanosheets with PEDOT NFs.

Fourier transform infrared spectroscopy (FT-IR) measurements were conducted for the PEDOT NFs before and after the incorporation of GO nanosheets and NiR enzyme molecules to further confirm the surface functionalization of GO and covalent interaction of NiR with PEDOT NFs (Figs. S5b-d in Supplementary Information). In the PEDOT NFs (Fig. S5b in Supplementary Information), the peaks at $1380-1521 \mathrm{~cm}^{-1}$ correspond to $\mathrm{C}-\mathrm{C}$ and $\mathrm{C}=\mathrm{C}$ stretching of quinoidal structure and ring stretching of thiophene ring. After the $\mathrm{GO}$ modification, the functional groups such as $\mathrm{C}-\mathrm{OH}, \mathrm{C}-\mathrm{O}-\mathrm{C}$, and $-\mathrm{COOH}$ at PEDOT NFs-GO composite appears. The sharp and overlapped peak at $1250 \mathrm{~cm}^{-1}$ corresponds to amide III, and the peak in the range of $1440-1640 \mathrm{~cm}^{-1}$ assigned due to the amide I indicating the enzyme immobilization. ${ }^{50}$ Detail of explaining FT-IR measurement results are provided in Supplementary Information. 
X-ray Photoelectron Spectroscopy (XPS) measurements were conducted to quantify various functional groups present at the fabricated PEDOT NFs, PEDOT NFs-GO, and NiR/PEDOT NFs-GO composite. Fig. S6a (Supplementary Information) shows the wide-scan spectra for the PEDOT NFs, the PEDOT NFs-GO, and the NiR/PEDOT NFs-GO films. After deconvolution of $S 2 p$, the three peaks found at $165.5 \mathrm{eV}, 169.3 \mathrm{eV}$, and $170.6 \mathrm{eV}$ corresponding to neutral S (S1), cationic $\mathrm{S}^{+}$(S2) associated with the PEDOT backbone, and highly oxidized sulfonate group (S3), respectively. ${ }^{51,52}$ Due to strong affinity of sulphur atom with $\mathrm{Au}$, the neutral sulphur species bind with Au surface via covalent interactions. The presence of sulfonate groups and cationic $\mathrm{S}^{+}$indicates the PEDOT NFs are positively charged (Fig. S6b-c, Supplementary Information). Thus, the negatively charged GO sheets can interact with PEDOT ${ }^{+}$ nanofibers via electrostatic interactions. ${ }^{53}$ Due to iron residues from FeTos during the polymerization of EDOT, two peaks are observed at 72 and $725 \mathrm{eV}$ assigning to Fe 2p3 and 2p1 contributions (Fig. S6d, Supplementary Information). The peak found for C 1 s core-level spectrum for PEDOT NFs is deconvoluted into two components at 286.7 and $286.7 \mathrm{eV}$ assigned to $\mathrm{O}-\mathrm{C}-\mathrm{O}$ (at.\%: ) in the $\beta$ position and $\mathrm{C}-\mathrm{O}-\mathrm{C}$ in the ethylene bridge in NFs (Fig. 4a). ${ }^{54}$ After the GO incorporation, the obtained characteristic peak for C1s is split into four peaks at 285.1, 286.8, 288.7 and $290.3 \mathrm{eV}$ corresponding to C-S or graphitic $\mathrm{C}-\mathrm{C}$, epoxy $\mathrm{C}-\mathrm{O}-\mathrm{C}$, carboxylic $\mathrm{O}-\mathrm{C}=\mathrm{O}$ (atomic concentration: $35.1 \%$ ) and carbonates, respectively, of GO nanosheets on PEDOT NFs. After the NiR immobilization, an additional peak in C 1s core-level spectrum is found at $287.2 \mathrm{eV}$ with a full-width half maxima (FWHM) of 1.62 assigned to amide bond $(\mathrm{N}-\mathrm{C}=\mathrm{O})$. Table $\mathrm{S} 3$ shows the binding energies, $\mathrm{FWHM}$ and corresponding atomic concentration of various deconvoluted peaks obtained from $\mathrm{C} 1 \mathrm{~s}, \mathrm{O} 1 \mathrm{~s}$ and $\mathrm{N} 1 \mathrm{~s}$. The formation of amide bond in the presence of EDC-NHS, a carboxylic acid at GO sheet binds covalently with an amine at NiR enzyme, leading to net gain of one amide bond by losing one $\mathrm{O}-\mathrm{C}=\mathrm{O}$. Thus, the atomic concentration of $\mathrm{O}-\mathrm{C}=\mathrm{O}$ in PEDOT NFs-GO is reduced to $20.3 \%$ after NiR immobilization indicating that the $\mathrm{O}-\mathrm{C}=\mathrm{O}$ groups play a role in forming amide bond on the surface of electrode. In the core-level spectrum of $\mathrm{O} 1 \mathrm{~s}$ (Fig. 4b, PEDOT NFs), two peaks at 533.1 and $535.2 \mathrm{eV}$ correspond to epoxy (C-O-C) and carbonyl $(\mathrm{C}=\mathrm{O})$ functional groups, respectively. The binding energies of these peaks that found in PEDOT NFs are slightly shifted with GO, however, the atomic concentration is increased to $18.5 \%$, and after the NiR treatment further it is increased to $32.5 \%$. The peaks of N 1s region in PEDOT are located at 399.1, 401.3 and 403.3 $\mathrm{eV}$, revealing uncharged deprotonated imine $(\mathrm{N} 1 ;-\mathrm{C}=\mathrm{N}-)$, nitrogen moieties $(\mathrm{N2} ;-\mathrm{NH}-)$, and protonated and hydrogen bonded amine $\left(\mathrm{N} 3 ;-\mathrm{NH}^{+}-\right)$, respectively, due to the utilization of pyridine and polyvinylpyrrolidone during the synthesis of PEDOT NFs (Fig. 4c). ${ }^{55}$ With the modification of GO sheets, PEDOT NFs show two peaks, i.e., N2 and N3, with higher binding energies. After the NiR immobilization, 
the peak obtained at $402.0 \mathrm{eV}$ with a high atomic concentration (89.8\%) is due to the formation of amide $(\mathrm{N}-\mathrm{C}=\mathrm{O})$ bond resulting from the EDC-NHS treated PEDOT NFs-GO and NiR enzyme. ${ }^{56}$

\subsection{Electrochemical characterization}

Cyclic voltammetry (CV) measurements (Fig. 5a) were conducted to study the interfacial properties and redox activity of the sensors with electrodes, including PEDOT NFs, PEDOT NFs-GO, and NiR/PEDOT NFs-GO composites. Their electrochemical peak current $\left(I_{\mathrm{p}}\right)$, peak-to-peak separation potential $(\Delta E)$, diffusion coefficient $(D)$, surface concentration $(\Gamma)$, electrochemical active surface area $\left(A_{e l}\right)$, and heterogeneous electron transfer rate $\left(k_{s}\right)$ were calculated using Eq. S2-S9 (Supplementary Information) and summarized in Table 1. Compared to the bare Au electrode, the PEDOT NFs have a higher electrochemical peak current of $1.13 \mathrm{~mA}$ on the order of a 3-time increase, and a lower peak-topeak separation voltage because of a fast electron transfer rate. The PEDOT NFs shows higher conductivity due to lack of existence of the undesired $\alpha, \beta$-and $\beta, \beta$-couplings within the polymer backbone. ${ }^{23,24}$ After the incorporation with GO nanosheets, the electrochemical surface area of the PEDOT NFs-GO composite becomes larger, while its redox activity is reduced and the peak current is reduced to $0.704 \mathrm{~mA}$, which may be caused by the presence of functional groups at $\mathrm{GO}$ nanosheets, ${ }^{57}$ such as $-\mathrm{COOH},-\mathrm{OH}$, and C-O. Srivastava et al. also described the reduction of electrochemical current

on $\mathrm{GO}$ electrode due to the existence of those functional groups. ${ }^{57}$ It is also found that the NiR enzyme functionalization onto the PEDOT NFs-GO reduces the redox current.

CV responses of the sensors with different electrodes were measured at different scan rates (10$100 \mathrm{mV} / \mathrm{s}$ ). The detailed response curves are given in Fig. S8 (Supplementary Information). With increasing scan rate, the peak-to-peak separation voltages for these electrodes shift toward higher potentials. Because the anodic and cathodic peak currents are proportional and inversely proportional with the square root of scan rate, respectively (Fig. 5b), all these electrodes show a surface-controlled process.

A maximum surface concentration of redox couple was obtained for the PEDOT NFs electrode. The high aspect ratio of the PEDOT NFs provides a higher diffusion coefficient, due to delocalized $\pi$ electron cloud overlaps in thiophene moiety and long-axis electron transportation with fibers. The surface concentration and diffusion coefficient consistently decreases due to the respective loading of GO nanosheets and protein molecules. The incorporation of GO sheets into the NFs also enhances the effective electrochemical area. A maximum $k_{s}$ value was obtained on the PEDOT NFs-GO electrode, 
compared to the other electrodes (Table 1 ). This is presumably due to the highly anisotropic tunneling conduction of electrons associated with the 1D feature of the polymer along the chains when intercalating with the benzoid structure of GO. The use of PEDOT NFs-GO enables a larger electrochemical surface area and a higher heterogeneous electron transfer rate than the use of PEDOT NFs only, leading to an improved sensor efficacy for quantification of nitrate ions. While the enzyme functionalization on the PEDOT NFs-GO results in a decrease in the ion diffusion coefficient of the electrode, the obtained high values of $k_{s}, D$ and $A_{e l}$ demonstrate that the NiR/PEDOT NFs-GO composite integrated in the microfluidic nitrate sensor performs as a suitable bioelectrode.

EIS measurements were used to measure the impedance of the electrode/electrolyte interface by applying a sinusoidal AC potential to the electrochemical cell. Fig. $5 c$ and $d$ show the EIS spectra for the fabricated sensors. A low $R_{\mathrm{ct}}$ value of $15.5 \Omega$ is found at the PEDOT NFs. The incorporation of GO nanosheets on the PEDOT NFs increases the value of $R_{\mathrm{ct}}$ to $35.6 \Omega$, due to the oxygenated functional groups available at GO nanosheets. After the NiR enzyme immobilization, the PEDOT NFs electrodes with and without $\mathrm{GO}$ exhibit increased values of $R_{\mathrm{ct}}$ due to the insulating nature of enzyme molecules on its surface. Among all the fabricated electrodes, the PEDOT NFs-GO electrode shows the highest value of $R_{\mathrm{ct}}$ at $126 \Omega$. Table $\mathrm{S} 4$ shows the electrochemical parameters, including $R_{\mathrm{ct}}, C_{\mathrm{dl}}$, and time constant $\tau$ obtained from the EIS spectra in Fig. 5c and d and Eq. S10-S14 (Supplementary Information). After the enzyme immobilization, the value of $\tau$ for the NiR/PEDOT NFs-GO electrode becomes higher than that for the NiR/PEDOT NFs (Table S4 in Supplementary Information), because of the slow diffusion of $\left[\mathrm{Fe}(\mathrm{CN})_{6}\right]^{3-/ 4-}$ ions at the electrode enzyme layer/solution interface.

\subsection{Detection of nitrate ions}

We first evaluated the ability of the constructed microfluidic sensor with the NiR/PEDOT NFs (without GO nanosheets) based bioelectrode to detect nitrate ions. The EIS measurement method was employed with the sensor. Synthetic solutions with different nitrate concentrations were used for this experiment, where a stock solution of $\mathrm{KNO}_{3}(1000 \mathrm{mg} / \mathrm{L})$ was prepared in de-ionized water and diluted into various concentrations from $0.044 \mathrm{mg} / \mathrm{L}$ to $442 \mathrm{mg} / \mathrm{L}$ of $\mathrm{NO}_{3}{ }^{-}$. Fig. 6a shows the Nyquist plots obtained by the EIS measurements. With increasing nitrate ion concentration, the value of $R_{\mathrm{ct}}$ decreased. Essentially, the nitrate ions at the surface of the electrode was reduced to nitrite ions and produces electrons, thus resulting in a reduced $R_{\mathrm{ct}}$. Fig. $6 \mathrm{~b}$ shows the sensor calibration plot for $R_{\mathrm{ct}}$ as a function of nitrate ion concentration. As the nitrate concentration increased from 0.044 to $0.44 \mathrm{mg} / \mathrm{L}$, 
the value of $R_{\mathrm{ct}}$ was not significantly reduced, but it was afterwards in the higher concentration range. The sensitivity of the sensor with the NiR/PEDOT NFs-based bioelectrode is found to be 24.35 $\Omega /(\mathrm{mg} / \mathrm{L}) / \mathrm{cm}^{2}$ within a wide nitrate concentration range from $0.44-442 \mathrm{mg} / \mathrm{L}$. The LOD of the sensor was calculated using the $3 \sigma_{\mathrm{b}} / m$ criteria, where $\sigma_{\mathrm{b}}$ and $m$ are the standard deviation and slope of the calibration curve. ${ }^{57}$ Using the NiR/PEDOT NFs, the sensor provided the LOD of $0.68 \mathrm{mg} / \mathrm{L}$ or ppm for detecting nitrate ions.

Next, to demonstrate the efficacy of GO nanosheets on the NiR/PEDOT NFs compared to the NiR/PEDOT NFs only, we conducted EIS measurements for this sensor with GO nanosheets. Fig. 7a and b show the EIS spectra for this sensor responding to different nitrate ion concentrations of both synthetic samples of nitrate ions $(0.044-442 \mathrm{mg} / \mathrm{L})$ and extracted solutions from soil samples $(0.044-44.2 \mathrm{mg} / \mathrm{L})$. Fig. 7c show that the value of $R_{\mathrm{ct}}$ decreased with increasing nitrate concentration of both the synthetic and real samples. The response curve of the sensor for the real samples well overlapped that for the synthetic samples, demonstrating the capability of this sensor to detect nitrate ions in the real samples extracted from soil. The relative standard deviation (RSD) for six repeated EIS measurements was as low as $2.9 \%$ and $3 \%$ for the synthetic and real samples, respectively. This microfluidic sensor had the higher sensitivity of $61.15 \Omega /(\mathrm{mg} / \mathrm{L}) / \mathrm{cm}^{2}$ in a range of nitrate ions concentration from 0.44 to $442 \mathrm{mg} / \mathrm{L}$ for the samples extracted from the soils, compared to that using the NiR/PEDOT NFs $\left(24.35 \Omega /(\mathrm{mg} / \mathrm{L}) / \mathrm{cm}^{2}\right)$.

Therefore, the graphitic nature of the coated GO nanosheets with sufficient oxygenated functional groups provided favorable impedimetric properties for the PEDOT NFs-GO composite electrode, improving the sensitivity of the sensor. A low LOD of $0.135 \mathrm{mg} / \mathrm{L}$ was obtained by this sensor with the PEDOT NFs-GO as the bioelectrode material, comparable to that with the PEDOT NFs alone $(0.68 \mathrm{mg} / \mathrm{L})$. By incorporating GO nanosheets in PEDOT NFs, this resulting nanocomposite can provide a larger electrochemical surface area and a higher charge transfer resistance for redox conversions as summarized in Table 1. The rich - $\mathrm{COOH},-\mathrm{CHO}$ groups present in this nanocomposite (especially in $\mathrm{GO}$ nanosheets) allow sufficient attachment of NiR enzyme molecules to the electrode surface, facilitating more catalytic conversion of nitrate to nitrite ions and thus generating more electrons and larger impedance variations in response to nitrate concentration. Fig. $7 \mathrm{~d}$ shows the transient response of this sensor to the presence of nitrate ions at the concentration of $8.82 \mathrm{mg} / \mathrm{L}$. Table 2 compares the performances between our sensors and other typical existing nitrate sensors. 


\subsection{Selectivity, stability and reproducibility studies}

To test selectivity of the fabricated sensors with the NiR/PEDOT NFs-GO and NiR/PEDOT NFs based bioelectrodes, we conducted EIS measurements with a fixed concentration of nitrate ions at 44.2 $\mathrm{mg} / \mathrm{L}$ (synthetic sample) in various interfering ions (Fig. 8a and Fig. S9a and b, Supplementary Information). As it is almost impossible to test the sensors with all possible interfering ions, only a few sample ions were tested to demonstrate selectivity of the bioelectrodes, including sulfate $\left(\mathrm{SO}_{4}{ }^{2-} ; 50 \mu \mathrm{M}\right.$ concentration), potassium $\left(\mathrm{K}^{+} ; 1.06 \mathrm{M}\right)$, chloride $\left(\mathrm{Cl}^{-} ; 0.94 \mathrm{M}\right)$, and bicarbonate $\left(\mathrm{HCO}_{3}{ }^{-} ; 100 \mu \mathrm{M}\right)$. These ions were chosen in the selectivity test because they are important anions and cations in soil. Because of the NiR enzyme immobilized on the surface of the sensors, the sensors were shown highly specific to nitrate ions even in presence of these high concentration interfering ions. The microfluidic sensors with the NiR/PEDOT NFs-GO and NiR/PEDOT NFs bioelectrodes exhibited minute changes in $R_{\mathrm{ct}}$ with these interfering ions, as evident by their low RSD of $\pm 1.51 \%$ and $\pm 2.15 \%$, respectively. In case of chloride for the sensor using the NiR/PEDOT NFs-GO bioelectrode, a maximum deviation of $4 \%$ from the initial value of $R_{\mathrm{ct}}$ was found, compared to other tested ions. For the device using the NiR/PEDOT NFs electrode, a maximum deviation of $\pm 3.2 \%$ from the initial value was observed with $\mathrm{HCO}_{3}{ }^{-}$ions.

The stability of the microfluidic sensor with the NiR/PEDOT NFs-GO and NiR/PEDOT NFs electrodes was evaluated by EIS measurements at regular intervals over 24 days (Fig. S9c-d, Supplementary Information). Fig. 8b shows the impedance responses of the NiR/PEDOT NFs-GO and NiR/PEDOT NFs electrodes-based sensors in presence of nitrate ions $(44.2 \mathrm{mg} / \mathrm{L})$ at a 3-day interval. The sensors were stable during the course of the measurement with only minute deviation from the initial signals. For the sensors with the NiR/PEDOT NFs-GO and NiR/PEDOT NFs electrodes, the RSD values were found to be $\pm 2.1 \%$ and $\pm 4.0 \%$, respectively, from their corresponding initial responses. We note that the results of the stability test through eight repeatable measurements over 24 days also reflected the reusability of our sensor.

To test the reproducibility of the sensor, we made three identical microfluidic sensors, with each using the NiR/PEDOT NFs-GO composite as its bioelectrode. Under the same condition these sensors were used to detect nitrate ions of a given concentration $(44.2 \mathrm{mg} / \mathrm{L})$ using the EIS method. Fig. $8 \mathrm{c}$ shows the EIS spectra of the sensors, where the inset gives a histogram plot for $R_{\mathrm{ct}}$ with respect to different sensors tested. Each sensor ran five repeated EIS measurements. The low RSD of $R_{\mathrm{ct}}( \pm 1 \%)$ from the initial signal indicates that the sensor offered good reproducibility. 


\section{Conclusions}

We demonstrated the microfluidic impedimetric sensor for specific detection of nitrate ion concentrations in the real samples extracted from soil. The sensor integrates the porous PEDOT NFs-GO composite at its WE and employs the EIS method to quantify nitrate ion concentrations. The covalent interactions between the PEDOT NFs-GO composite and Au surface by S-Au bonding as evidenced by the XPS studies facilitate easy surface modification of the WE in this device. The NiR enzyme molecules immobilized onto the surface of the PEDOT NFs-GO composite allow for specific detection of nitrate ions even in presence of other interfering ions. The abundant functional groups at GO contribute to strong covalent conjugation with NiR enzyme resulting in a higher charge transfer resistance in this device. Due to the large electrochemical surface area of the PEDOT NFs-GO composite, the loading capability for NiR enzyme of the WE is increased, thus widening the detection concentration range of the sensor. In this sensor, the GO incorporation allows enhancing the sensitivity over a test range of $0.044-442 \mathrm{mg} / \mathrm{L}$ nitrate ions. The sensor also demonstrates good selectivity, stability and reproducibility. Efforts are being made to use this microfluidic device for detection of multiple ions, including phosphate and potassium by making an array of electrodes with specific enzyme molecules.

\section{Acknowledgements}

This work is supported in part by the lowa State University's Plant Sciences Institute, the lowa Corn Promotion Board, the U.S. National Science Foundation under grants DBI-1353819, CCF-1331390, and DGE-1545453, and the United State Department of Agriculture under grant 2013-68004-20374. 


\section{References}

[1] R. W. Jones, S. J. Rathke, D. A. Laird and J. F. McClelland, Real-time sensing of soil nitrate concentration in the parts per million range while the soil is in motion, Appl. Spectrosc. 67 (2013) 11061110.

[2] J. A. Silva, C. I. Evensen, R. L. Bowen, R. Kirby, G. Y. Tsuji, and R. S. Yost, Managing fertilizer nutrients to protect the environment and human health, Plant Nutrient Management in Hawaii's Soils, University of Hawaii at Manoa: College of Tropical Agriculture and Human Resources, Manoa, 2000, 7-22.

[3] S. Cosnier, C. Innocent and Y. Jouanneau, Amperometric detection of nitrate via a nitrate reductase immobilized and electrically wired at the electrode surface, Anal. Chem. 66 (1994) 3198-3201.

[4] V. Mani, A. P. Periasamy, S.-M. Chen, Highly selective amperometric nitrite sensor based on chemically reduced graphene oxide modified electrode, Electrochem. Commun. 17 (2012) 75-78.

[5] L. M. Moretto, P. Ugo, M. Zanata, P. Guerriero, C. R. Martin, Nitrate biosensor based on the ultrathinfilm composite membrane concept, Anal. Chem. 70 (1998) 2163-2166.

[6] J. W. Aylott, D. J. Richardson, D. A. Russell, Optical biosensing of nitrate ions using a sol-gel immobilized nitrate reductase, Analyst 122 (1997) 77-80.

[7] X. J. Wang, S. V. Dzyadevych, J. M. Chovelon, N. J. Renault, L. Chen, S. Q. Xia, J. F. Zhao, Development of a conductometric nitrate biosensor based on methyl viologen/nafion ${ }^{\circledR}$ composite film, Electrochem. Commun. 8 (2006) 201-205.

[8] A. A. Gokhale, J. Lu, R. R. Weerasiri, J. Yu, I. Lee, Amperometric detection and quantification of nitrate ions using a highly sensitive nanostructured membrane electrocodeposited biosensor array, Electroanalysis 27 (2015) 1127-1137.

[9] N. J. Ronkainen, H. B. Halsall, W. R. Heineman, Electrochemical biosensors, Chem. Soc. Rev. 39 (2010) 1747-1763.

[10] Md. A. Ali, S. Srivastava, K. Mondal, P. M. Chavhan, V.V. Agrawal, R. John, A. Sharma, B. D. Malhotra, A surface functionalized nanoporous titania integrated microfluidic biochip, Nanoscale 6 (2014) 1395813969.

[11] H. Chang, Y. Yuan, N. Shi, Y. Guan, Electrochemical DNA biosensor based on conducting polyaniline nanotube array, Anal. Chem. 79 (2007) 5111-5115.

[12] H. Peng, L. Zhang, J. Spires, C. Soeller, J. Travas-Sejdic, Synthesis of a functionalized polythiophene as an active substrate for a label-free electrochemical genosensor, Polymer 48 (2007) 3413-3419.

[13] X. Y. Wang, Y. G. Kim, C. Drew, B. C. Ku, J. Kumar, L. A. Samuelson, Electrostatic assembly of conjugated polymer thin layers on electrospun nanofibrous membranes for biosensors, Nano Lett. 4 (2004) 331-334.

[14] K. Markušová, Determination of nitrate in natural waters by voltammetry at a stationary mercury drop electrode, Anal. Chim. Acta 221 (1989) 131-138.

[15] C. Neuhold, K. Kalcher, W. Diewald, X. H. Cai, G. Raber, Voltammetric determination of nitrate with a modified carbon paste electrode, Electroanalysis 6 (1994) 227-236. 
[16] L. Ma, B. Y. Zhang, H. L. Li, J. Q. Chambers, Kinetics of nitrate reduction by cobalt-cyclam incorporated nafion ${ }^{\circledR}$ redox polymer, J. Electroanal. Chem. 362 (1993) 201-205.

[17] P. Ugo, L. M. Moretto, B. Ballarin, Nitrate detection at nafion-modified electrodes incorporating ytterbium and uranyl electrocatalysts, Electroanalysis 7 (1995) 129-131.

[18] C. M. Welch, M. E. Hyde, C. E. Banks, R. G. Compton, The detection of nitrate using in-situ copper nanoparticle deposition at a boron doped diamond electrode, Anal. Sci. 21 (2005) 1421-30.

[19] B. Hafezi, M. R. Majidi, A sensitive and fast electrochemical sensor based on copper nanostructures for nitrate determination in foodstuffs and mineral waters, Anal. Methods. 5 (2013) 3552-6.

[20] H. D. Tran, D. Li, R. B. Kaner, One-dimensional conducting polymer nanostructures: bulk synthesis and applications, Adv. Mater. 21 (2009) 487-499.

[21] L. Xia, Z. Wei, M. Wan, Conducting polymer nanostructures and their application in biosensors, J. Colloid Interface Sci. 341 (2010) 1-11.

[22] J. A. Arter, D. K. Taggart, T. M. McIntire, R. M. Penner, G. A. Weiss, Virus-PEDOT nanowires for biosensing, Nano Lett. 10 (2010) 4858-4862.

[23] G. Yang, K. L. Kampstra, M. R. Abidian, High performance conducting polymer nanofiber biosensors for detection of biomolecules, Adv. Mater. 26 (2014) 4954-4960.

[24] H. Zhou, W. Yao, G. Li, J. Wang, Y. Lu, Graphene/poly (3, 4-ethylenedioxythiophene) hydrogel with excellent mechanical performance and high conductivity, Carbon 59 (2013) 495-502.

[25] S. M. Richardson-Burns, J. L. Hendricks, B. Foster, L. K. Povlich, D.-H. Kim, D. C. Martin, Polymerization of the conducting polymer poly (3, 4-ethylenedioxythiophene) (PEDOT) around living neural cells, Biomaterials 28 (2007) 1539-1552.

[26] C. M. Hangarter, M. Bangar, A. Mulchandani, N. V. Myung, Conducting polymer nanowires for chemiresistive and fet-based bio/chemical sensors, J. Mater. Chem. 20 (2010) 3131-3140.

[27] A. Kros, R. J. M. Nolte, N. Sommerdijk, Conducting polymers with confined dimensions: track-etch membranes for amperometric biosensor applications, Adv. Mater. 14 (2002) 1779-1782.

[28] A. Wisitsoraat, S. Pakapongpan, C. Sriprachuabwong, D. Phokharatkul, P. Sritongkham, T. Lomas, A. Tuantranont, Graphene-PEDOT:PSS on screen printed carbon electrode for enzymatic biosensing, J. Electroanal. Chem. 704 (2013) 208-213.

[29] C.-Y. Chu, J.-T. Tsai, C.-L. Sun, Synthesis of PEDOT-modified graphene composite materials as flexible electrodes for energy storage and conversion applications, Int. J. Hydrogen Energy 37 (2012) 1388013886.

[30] T. Y, Huang, C. W. Kung, H. Y. Wei, K. M. Boopathi, C. W. Chu, K. C. Ho, A high performance electrochemical sensor for acetaminophen based on a rGO-PEDOT nanotube composite modified electrode, J. Mater. Chem. A, 2 (2014) 7229-7237.

[31] L. M. Lu, O. Zhang, J. K. Xu, Y. P. Wen, X. M. Duan, H. M. Yu, L. P. Wu, T. Nie, A facile one-step redox route for the synthesis of graphene/poly (3,4-ethylenedioxythiophene) nanocomposite and their applications in biosensing, Sens and Actuat. B, 181 (2013) 567-574. 
[32] D. Y. Lee, S. I. Na, S. S. Kim, Graphene oxide/PEDOT: PSS composite hole transport layer for efficient and stable planar heterojunction perovskite solar cells, Nanoscale 8 (2016) 1513-1522.

[33] S. Lehtimäki, M. Suominen, P. Damlin, S. Tuukkanen, C. Kvarnstrom, D. Lupo, Preparation of supercapacitors on flexible substrates with electrodeposited PEDOT/graphene composites. ACS Appl. Mater. Interfaces 7 (2015) 22137-22147.

[34] D. Yoo, J. Kim, J. H. Kim, Direct synthesis of highly conductive poly (3, 4-ethylenedioxythiophene): poly (4-styrenesulfonate)(PEDOT: PSS)/graphene composites and their applications in energy harvesting systems, Nano Research 7 (2014) 717-730.

[35] M. Zhang, W. Yuan, B. Yao, C. Li, G. Shi, Solution-processed pedot: pss/graphene composites as the electrocatalyst for oxygen reduction reaction, ACS Appl. Mater. Interfaces 6 (2014) 3587-3593.

[36] N. Hui, W. Wang, G. Xu, X. Luo, Graphene oxide doped poly (3, 4-ethylenedioxythiophene) modified with copper nanoparticles for high performance nonenzymatic sensing of glucose, J. Mater. Chem. B 3 (2015) 556-561.

[37] J. Xu, R. Peng, Q. Ran, Y. Xian, Y. Tian, L. Jin, A highly soluble poly (3, 4-ethylenedioxythiophene)poly (styrene sulfonic acid)/Au nanocomposite for horseradish peroxidase immobilization and biosensing, Talanta 82 (2010) 1511-1515.

[38] Y. Xia, H. Zhang, J. Ouyang, Highly conductive PEDOT: PSS films prepared through a treatment with zwitterions and their application in polymer photovoltaic cells, J. Mater. Chem. 20 (2010) 9740-9747.

[39] P. Santhosh, K. M. Manesh, S. Uthayakumar, S. Komathi, A. I. Gopalan, K. P. Lee, Fabrication of enzymatic glucose biosensor based on palladium nanoparticles dispersed onto poly (3, 4ethylenedioxythiophene) nanofibers, Bioelectrochemistry 75 (2009) 61-66.

[40] Y. Yang, X. Yang, W. Yang, S. Li, J. Xu, Y. Jiang, Porous conducting polymer and reduced graphene oxide nanocomposites for room temperature gas detection, RSC Adv. 4 (2014) 42546-42553.

[41] J. Zhang, F. Zhang, H. Yang, X. Huang, H. Liu, J. Zhang, S. Guo, Graphene oxide as a matrix for enzyme immobilization, Langmuir 26 (2010) 6083-6085.

[42] S. Nair, E. Hsiao, S. H. Kim, Melt-welding and improved electrical conductivity of nonwoven porous nanofiber mats of poly (3, 4-ethylenedioxythiophene) grown on electrospun polystyrene fiber template, Chem. Mater. 21 (2008) 115-121.

[43] S. J. Park, H. S. Song, O. S. Kwon, J. H. Chung, S. H. Lee, J. H. An, S. R. Ahn, J. E. Lee, H. Yoon, T. H. Park, J. Jang, Human dopamine receptor nanovesicles for gate-potential modulators in highperformance field-effect transistor biosensors, Sci. Rep. 4 (2014) 4342.

[44] H.-B. Bu, G. Götz, E. Reinold, A. Vogt, S. Schmid, R. Blanco, J. L. Segura, P. Bäuerle, "Click"functionalization of conducting poly (3, 4-ethylenedioxythiophene) (PEDOT), Chem. Commun. 11 (2008) 1320-1322.

[45] S.-C. Luo, E. M. Ali, N. C. Tansil, H.-H. Yu, S. Gao, E. A. B. Kantchev, J. Y. Ying, Poly (3, 4ethylenedioxythiophene) (PEDOT) nanobiointerfaces: Thin, ultrasmooth, and functionalized PEDOT films with In Vitro and In Vivo biocompatibility, Langmuir 24 (2008) 8071-8077. 
[46] S.-C. Luo, S. S. Liour, H.-h. Yu, Perfluoro-functionalized PEDOT films with controlled morphology as superhydrophobic coatings and biointerfaces with enhanced cell adhesion, Chem. Commun. 46 (2010) 4731-4733.

[47] A. J. Demello, Control and detection of chemical reactions in microfluidic systems, Nature, 442 (2006) 394-402.

[48] M. A. Ali, K. K. Reza, S. Srivastava, V. V. Agrawal, R. John, B. D. Malhotra, Lipid-lipid interactions in aminated reduced graphene oxide interface for biosensing application, Langmuir 30 (2014) 4192-4201.

[49] R. Hood-Nowotny, N. Hinko-Najera Umana, E. Inselbacher, P. Oswald-Lachouani and W. Wanek, Alternative methods for measuring inorganic, organic, and total dissolved nitrogen in soil, Soil Sci. Soc. Am. J. 74 (2010) 1018-1027.

[50] M. A. Rahman, N.-H. Kwon, M.-S. Won, E. S. Choe, Y.-B. Shim, Functionalized conducting polymer as an enzyme-immobilizing substrate: an amperometric glutamate microbiosensor for In Vivo measurements, Anal. Chem. 77 (2005) 4854-4860.

[51] X. Bai, X. Hu, S. Zhou, J. Yan, C. Sun, P. Chen, and L. Li, Controlled fabrication of highly conductive three-dimensional flowerlike poly (3, 4-ethylenedioxythiophene) nanostructures, J. Mater. Chem. 21 (2011) 7123-7129.

[52] J. Noh, E. Ito, K. Nakajima, J. Kim, H. Lee and M. Hara, High-resolution STM and XPS studies of thiophene self-assembled monolayers on Au (111), J. Phys. Chem. B 106 (2002) 7139-7141.

[53] J. H. Jung, D. S. Cheon, F. Liu, K. B. Lee, T. S. Seo, A graphene oxide based immuno-biosensor for pathogen detection, Angew. Chem. Int. Ed. 49 (2010) 5708-5711.

[54] C. Chen, T. Zhang, Q. Zhang, Z. Feng, C. Zhu, Y. Yu, K. Li, M. Zhao, J. Yang, J. Liu, D. Sun, Threedimensional BC/PEDOT composite nanofibers with high performance for electrode-cell Interface, ACS Appl. Mater. Interfaces 7 (2015) 28244-28253.

[55] X. Luo, C. L. Weaver, S. Tan, X. T. Cui, Pure graphene oxide doped conducting polymer nanocomposite for bio-interfacing, J. Mater. Chem. B, 1 (2013) 1340-1348.

[56] D. Du, L. Wang, Y. Shao, J. Wang, M. H. Engelhard, Y. Lin, Functionalized graphene oxide as a nanocarrier in a multienzyme labeling amplification strategy for ultrasensitive electrochemical immunoassay of phosphorylated p53 (S392), Anal. Chem. 83 (2011) 746-752.

[57] S. Srivastava, S. Abraham, C. Singh, Md. A. Ali, A. Srivastava, G. Sumana, B. D. Malhotra, Protein conjugated carboxylated gold@ reduced graphene oxide for aflatoxin B 1 detection, RSC Adv. 5 (2015) 5406-5414.

[58] F. Can, S. K. Ozoner, P. Ergenekon, E. Erhan, Amperometric nitrate biosensor based on Carbon nanotube/Polypyrrole/Nitrate reductase biofilm electrode, Mater. Sci. Eng. C 32 (2012) 18-23.

[59] M. Sohail, S. B. Adeloju, Fabrication of redox-mediator supported potentiometric nitrate biosensor with nitrate reductase, Electroanalysis, 21 (2009) 1411-1418. 


\section{Captions of Tables and Figures}

Table 1. Electrochemical parameters of various fabricated electrodes.

Table 2. Performance comparison between our sensors and other typical existing nitrate sensors

Figure 1. (a) Photo of the fabricated microfludic sensor using PEDOT NFs-GO composites to modifiy the working electrode of the sensor for detection of nitrate ions. The channel was loaded with food dye for easy visualization. (b) Scanning electron microscopic (SEM) image for the PEDOT NFs-GO composite. (c) Geometry and layout of the working electrode of the sensor. (d) Schematic of the surface immobilization of PEDOT NFs-GO with NiR enzyme to realize electrochemical nitrate detection by catalytic conversion of nitrate to nitrite.

Figure 2 SEM micrographs of as-synthesized PEDOT NFs (a), dispersed PEDOT NFs deposited on the surface of Au electrode (b), tip of a PEDOT nanorod (c), GO nanosheets decorated PEDOT nanofibers (PEDOT NFs-GO composite) deposited on Au electrode (d), tip of a PEDOT nanorod (e), tip of PEDOT NFs coated with GO (e), and detail of the surface of PEDOT NF-GO.

Figure 3 TEM images of PEDOT NFs (a-c) and GO nanosheets (d-e). Inset of (b) shows TEM image for a bundle of PEDOT NFs. Image (f) shows the SAED pattern of GO nanosheets. Images (g-i) show the PEDOT NFs coated with GO. Inset of (i) gives the SAED pattern of PEDOT NFs-GO composite.

Figure 4. XPS spectra for $C 1 s$ (a), $O$ is (b) and $N$ 1s (c) for PEDOT NFs, PEDOT NFs-GO and NiR/PEDOT NFs-GO films, respectively, with high-resolution deconvoluted peaks.

Figure 5. (a) CV studies for comparison of different electrodes at a scan rate of $20 \mathrm{mV} / \mathrm{s}$ in $50 \mathrm{mM}$ PBS $(0.9 \% \mathrm{NaCl} ; \mathrm{pH}: 7.0)$ using $5 \mathrm{mM} \mathrm{K}{ }_{3}\left[\mathrm{Fe}(\mathrm{CN})_{6}\right]^{3-/ 4-}$ as a redox mediator. (b) Anodic and cathodic peak current variation as a function of square root of scan rate for the different electrodes. (c) Nyquist plot and corresponding fitting for Au electrode by EIS method for calculating $R_{\mathrm{ct}}$ and $C_{\mathrm{dl}}$ values. The semicircle and straight regions indicate kinetic and mass transfer control. Inset shows the equivalent circuit model for EIS spectra. The amplitude was set to $1 \mathrm{mV}$, bias potential was at $1 \mathrm{mV}$, and frequency range was set to $1.0 \mathrm{~Hz}$ to $100 \times 10^{3} \mathrm{~Hz}$. (d) EIS spectra for the PEDOT NFs and PEDOT NFs-GO electrodes before and after the NiR immobilization. 
Figure 6. (a) Electrochemical impedance responses of the fabricated NiR/PEDOT NFs bioelectrode as a function of nitrate ions. (b) $R_{\mathrm{ct}}$ of the sensor as a function of nitrate concentration for NiR/PEDOT NFs bioelectrode. Error bars are obtained from three repeated measurements.

Figure 7. (a, b) EIS spectra for NiR/PEDOT NFs-GO bioelectrode as a function of nitrate concentration of synthetic samples, and real sample extracted from soil, respectively. (c) $R_{\mathrm{ct}}$ of the sensor as a function of concentration of nitrate ions for both synthetic and real samples. (d) Transient response of the sensor to the presence of nitrate ions at the given concentration of $8.82 \mathrm{mg} / \mathrm{L}$.

Figure 8. (a) $R_{\mathrm{ct}}$ of the NiR/PEDOT NFs-GO and NiR/PEDOT NFs bioelectrodes in the presence of various interfering ions for selectivity studies. (a) $R_{\mathrm{ct}}$ of the NiR/PEDOT NFs-GO and NiR/PEDOT NFs bioelectrodes tested for 24 days. (c) EIS spectra for three NiR/PEDOT NFs-GO based nitrate sensors at $44.2 \mathrm{mg} / \mathrm{L}$ nitrate concentration. Inset shows a histogram plot for $R_{\mathrm{ct}}$ with respect to the three sensors. Error bars are obtained from five repeated measurements. 


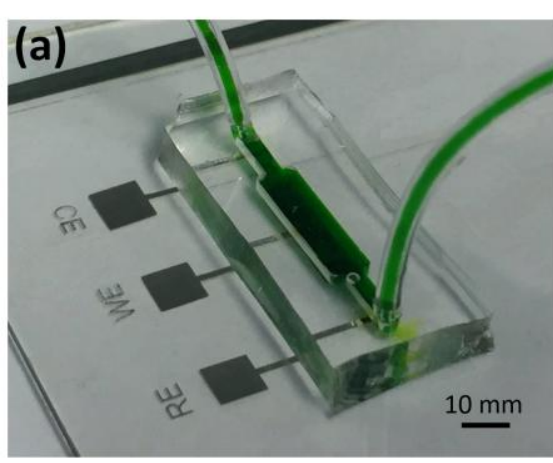

(b)

(d)

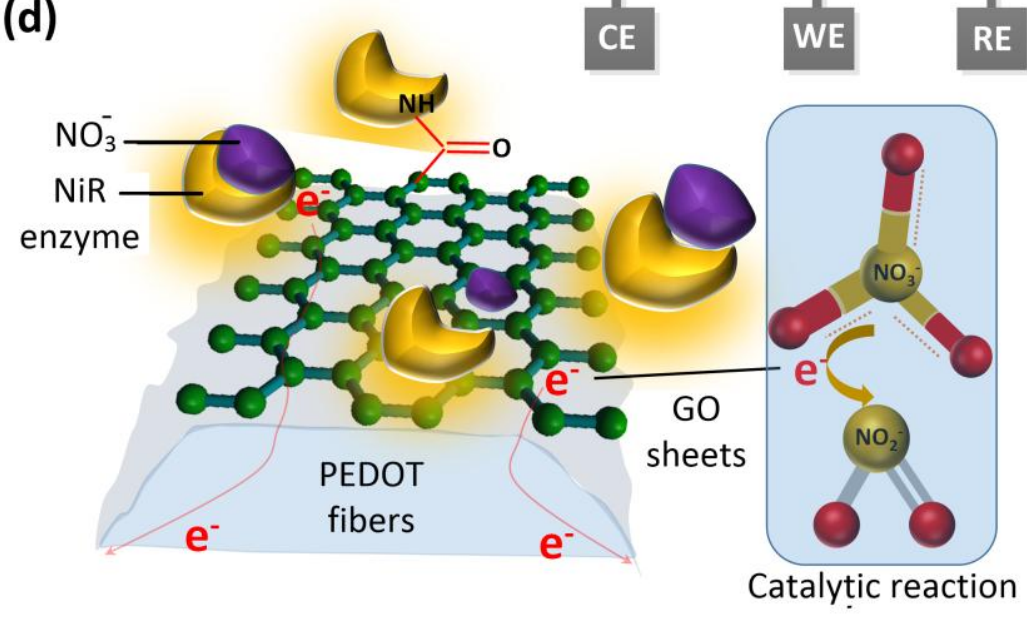




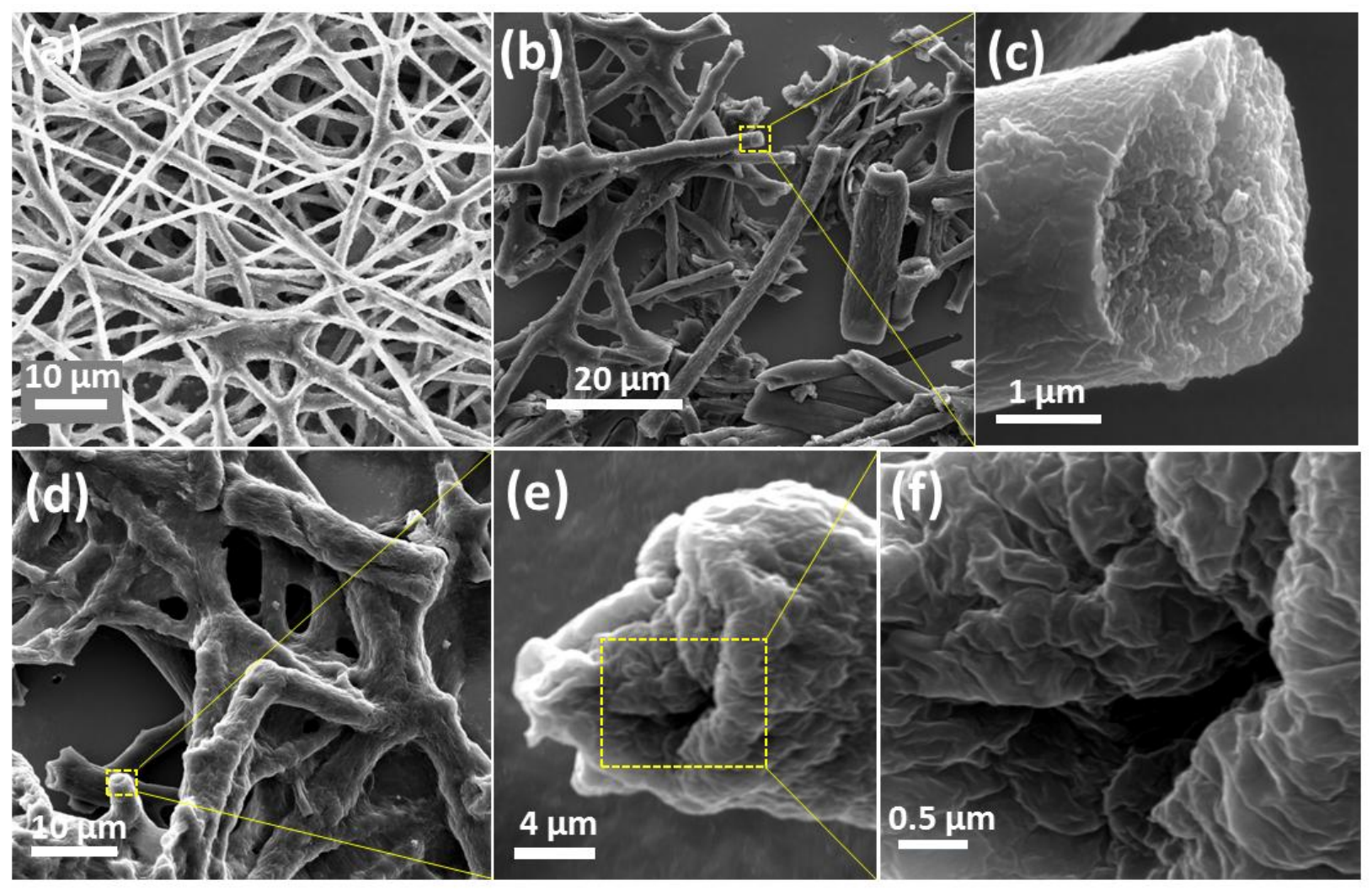




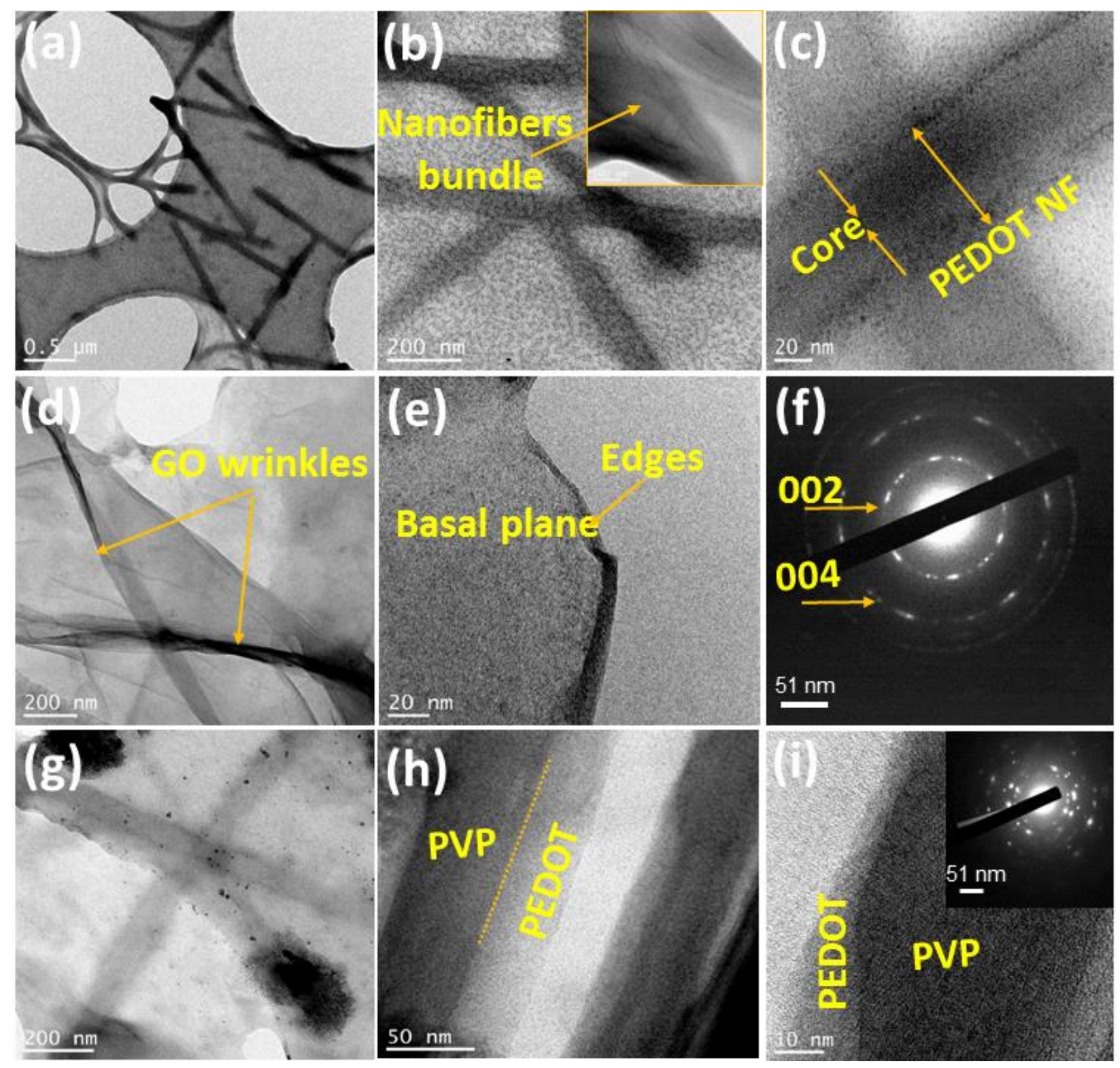


(a)

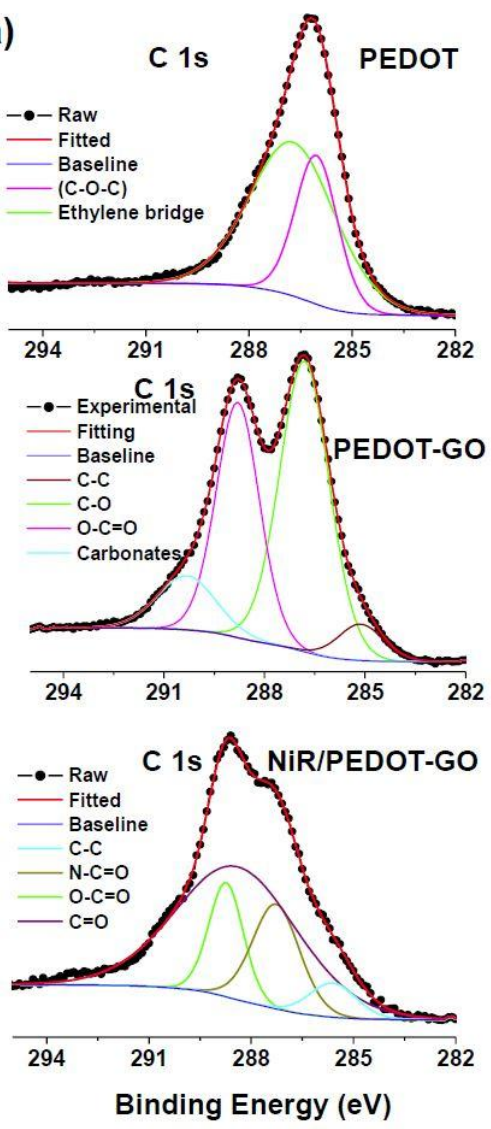

(b)
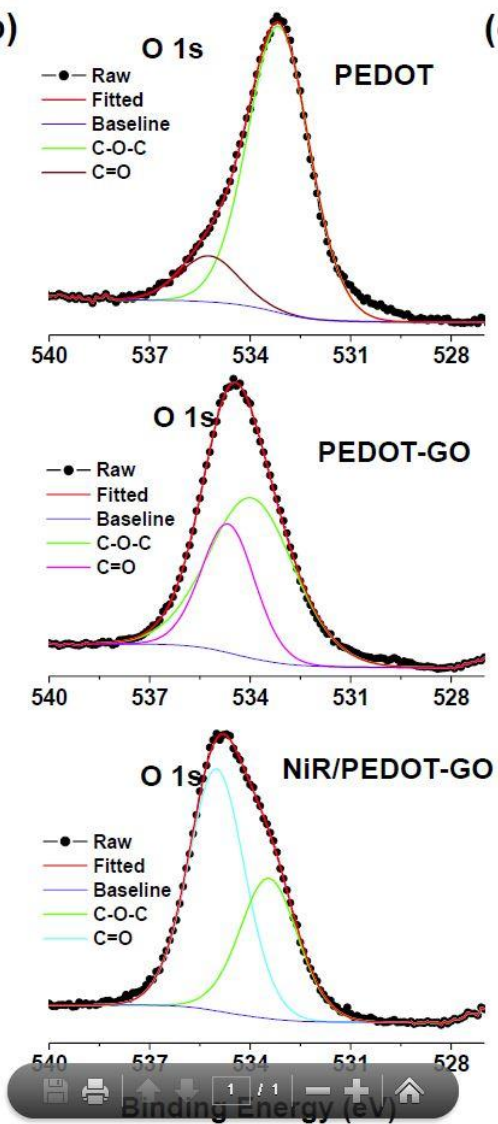

(c)
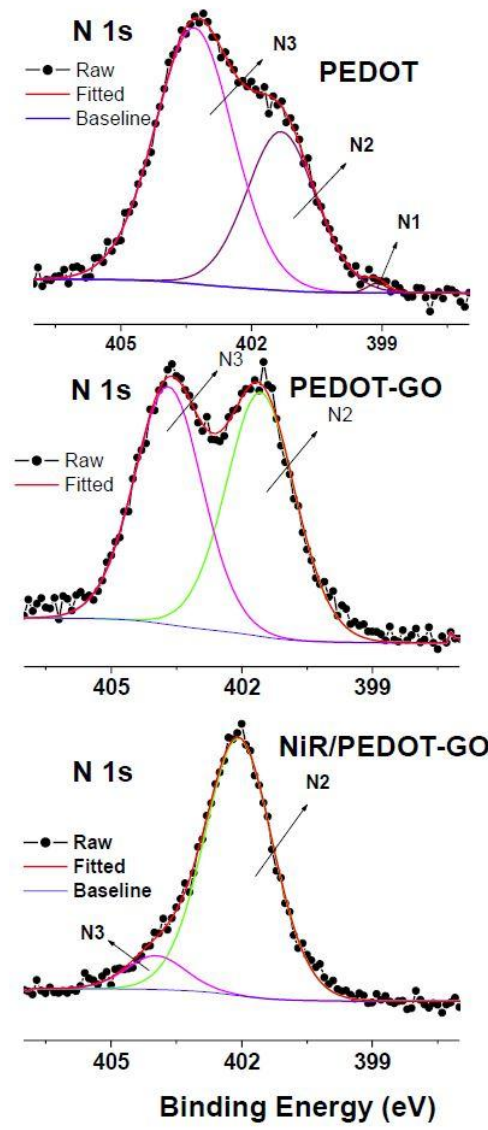

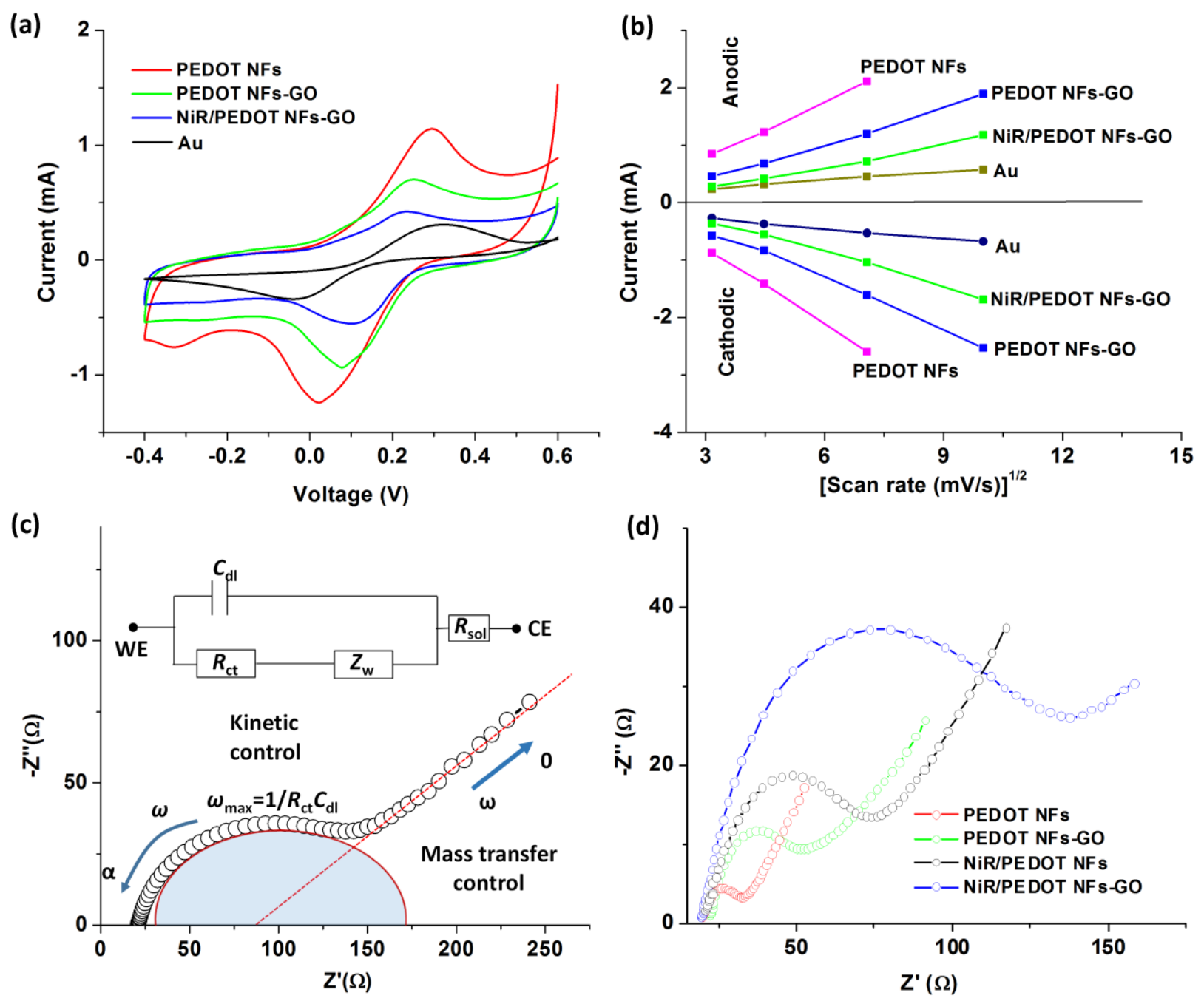

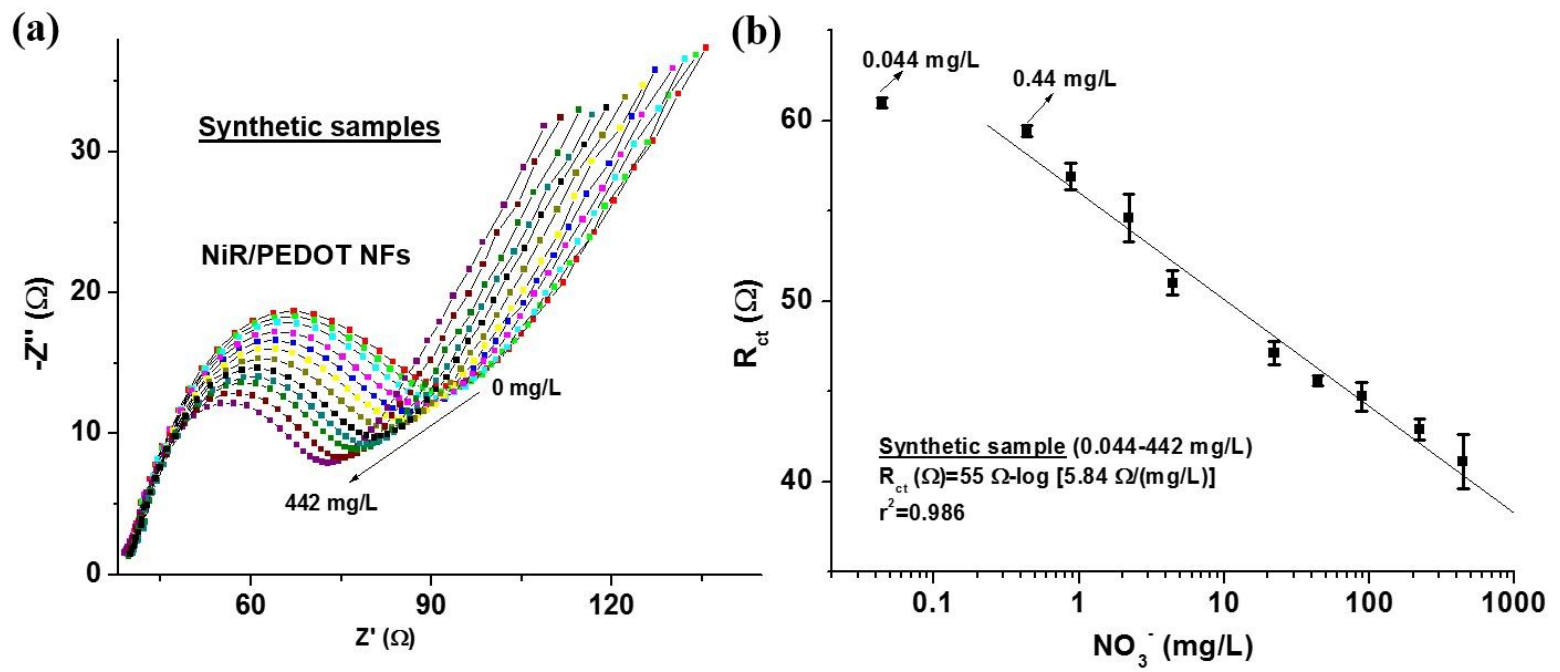
(a)

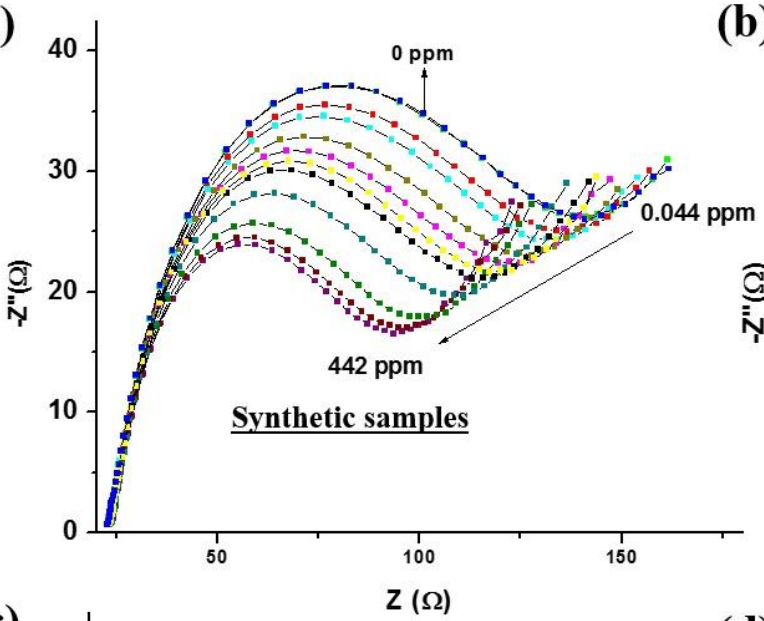

(c)

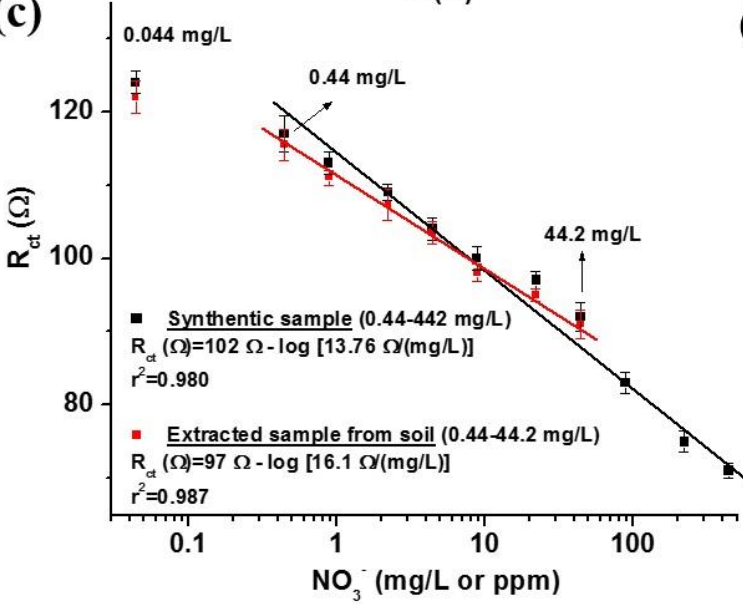

(d) (b)
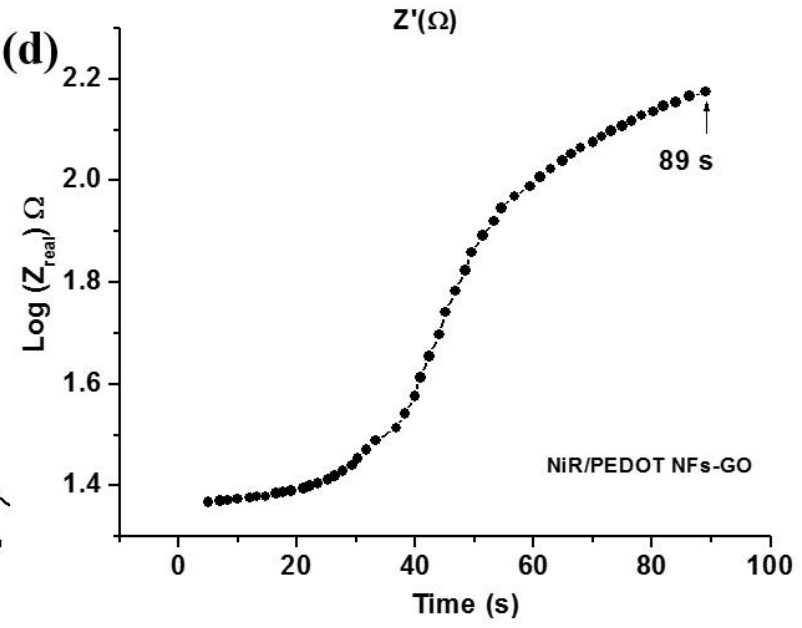

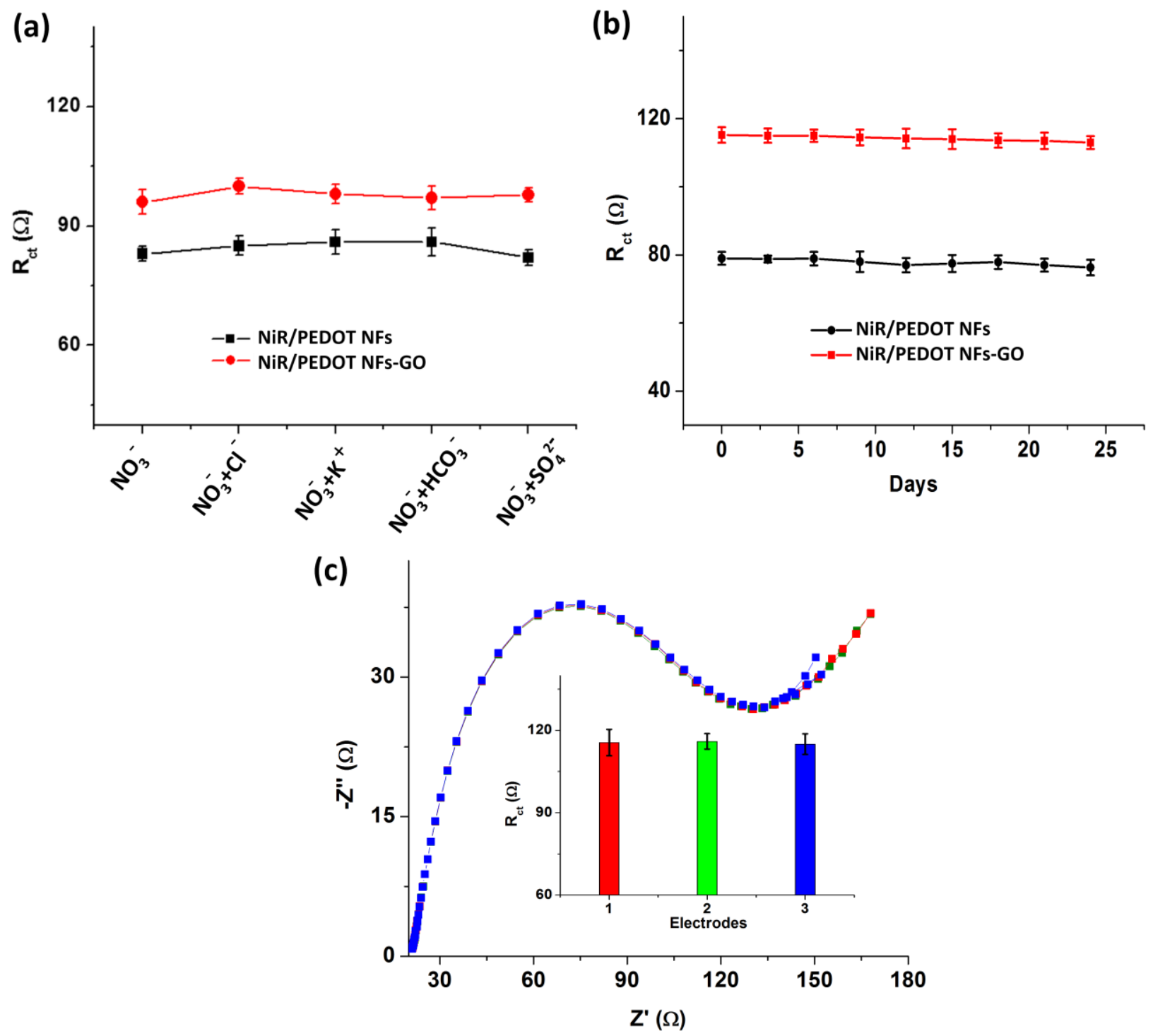
Table 1. Electrochemical parameters of various fabricated electrodes.

\begin{tabular}{lllllll}
\hline Electrodes & $\begin{array}{l}\text { Peak } \\
\text { Current } \\
\boldsymbol{I}_{\mathrm{p}}(\mathrm{mA})\end{array}$ & $\begin{array}{l}\text { Peak-to-peak } \\
\text { separation } \\
\text { voltage } \Delta \mathrm{E}(\mathrm{V})\end{array}$ & $\begin{array}{l}\text { Surface } \\
\text { concentration } \\
\boldsymbol{\Gamma}\left(\mathbf{m o l} / \mathbf{c m}^{2}\right)\end{array}$ & $\begin{array}{l}\text { Diffusion } \\
\text { coefficient } \\
\boldsymbol{D}\left(\mathbf{c m}^{2} / \mathbf{s}\right)\end{array}$ & $\begin{array}{l}\text { Electro- } \\
\text { chemical } \\
\text { Area } \boldsymbol{A}_{\boldsymbol{e l}}\left(\mathbf{c m}^{2}\right)\end{array}$ & $\begin{array}{l}\text { Heterogeneous } \\
\text { electron rate } \boldsymbol{k}_{\boldsymbol{s}} \\
\left(\mathbf{c m s}^{-1}\right)\end{array}$ \\
\hline $\mathrm{Au}$ & 0.312 & 0.345 & $5.3 \times 10^{-10}$ & $52.03 \times 10^{-7}$ & 0.144 & $1.05 \times 10^{-4}$ \\
PEDOT NFs & 1.13 & 0.275 & $4.6 \times 10^{-11}$ & $68.25 \times 10^{-6}$ & 0.264 & $7.5 \times 10^{-4}$ \\
PEDOT NFs-GO & 0.704 & 0.172 & $2.33 \times 10^{-11}$ & $26.49 \times 10^{-6}$ & 0.273 & $12.4 \times 10^{-4}$ \\
NiR/PEDOT NFs-GO & 0.429 & 0.128 & $1.45 \times 10^{-11}$ & $98.37 \times 10^{-7}$ & 0.280 & $12.0 \times 10^{-4}$ \\
\hline
\end{tabular}


Table 2. Performance comparison between our sensors and other typical existing nitrate sensors.

\begin{tabular}{c|c|c|c|c}
\hline Bioelectrode Materials & $\begin{array}{c}\text { Measurement } \\
\text { Methods }\end{array}$ & Nitrate Con. Range & Sensitivity & Ref. \\
\hline Reduced GO & Amperometry & $8.9-167 \mu \mathrm{M}$ & $27 \mathrm{nA} / \mu \mathrm{M} / \mathrm{cm}^{2}$ & $(4)$ \\
\hline $\begin{array}{c}\text { 1-methyl-3-(pyrrol-1- } \\
\text { ylmethyl) pyridinium }\end{array}$ & Amperometry & $100 \mu \mathrm{M}$ & $78 \mathrm{nA} / \mu \mathrm{M} / \mathrm{cm}^{2}$ & $(5)$ \\
\hline Periplasmic NiR & UV-visible absorption & $1.5 \mu \mathrm{M}$ & $\mathrm{NA}$ & $(6)$ \\
\hline Methyl viologen/Nafion & Conductance & $20-250 \mu \mathrm{M}$ & $\mathrm{NA}$ & $(7)$ \\
\hline CNT/Polypyrrole/NiR & Amperometry & $440-1450 \mu \mathrm{M}$ & $0.3 \mathrm{nA} / \mu \mathrm{M} / \mathrm{cm}^{2}$ & $(58)$ \\
\hline NiR/Polypyrrole & Potentiometric & $50-5000 \mu \mathrm{M}$ & $\mathrm{NA}$ & $(59)$ \\
\hline NiR/PEDOT NFs & Impedance & $\begin{array}{c}0.44-442 \mathrm{mg} / \mathrm{L} \text { or } \\
7.09-7128 \mu \mathrm{M}\end{array}$ & $\begin{array}{c}24.35 \Omega /(\mathrm{mg} / \mathrm{L}) / \mathrm{cm}^{2} \text { or } \\
1.51 \Omega / \mu \mathrm{M} / \mathrm{cm}^{2}\end{array}$ & This work \\
\hline NiR/PEDOT NFs-GO & Impedance & $\begin{array}{c}0.44-442 \mathrm{mg} / \mathrm{L} \text { or } \\
7.09-7128 \mu \mathrm{M}\end{array}$ & $\begin{array}{c}61.15 \Omega /(\mathrm{mg} / \mathrm{L}) / \mathrm{cm}^{2} \text { or } \\
3.8 \Omega / \mu \mathrm{M} / \mathrm{cm}^{2}\end{array}$ & This work \\
\hline
\end{tabular}

